\title{
TRADUÇÃO
}

\section{A ORIGEM DA MELODIA ${ }^{1}$}

Jean-Jacques Rousseau

Tradução de Evaldo Becker

Parece-me pois que a Melodia ou o canto, pura obra da natureza, não deve nem segundo os sábios, nem segundo os ignorantes sua origem à harmonia, obra e produção da arte, que serve como prova e não como fonte ao belo canto e cuja mais nobre função é a de fazê-lo valer.

Mas procuremos, se for possível, a verdadeira origem da melodia, e vejamos se a ideia que o Sr. Rameau dela concebeu está de acordo com aquela que nos fornece a exata observação dos fatos. Como é preciso para isso voltar às fontes; após ter advertido os leitores que queiram me seguir de se armar de paciência, eu serei sem escrúpulos, tão prolixo quanto me aprouver.

Nós ignoramos tão perfeitamente o estado natural do homem que não sabemos nem mesmo se existe algum tipo de grito que lhe seja próprio; em compensação, nós o conhecemos como um animal imitador que não tarda a se apropriar de todas as faculdades que ele pode extrair dos exemplos dos outros animais. Ele poderá então, de início, imitar os gritos daqueles que o cercam, e segundo as diversas espécies que habitam cada rincão (contrée), os homens, antes mesmo de possuírem línguas, puderam ter gritos diferentes de um país ao outro. Além disso, os órgãos estavam mais ou menos soltos (Déliés) e flexíveis segundo a temperatura dos climas e eis aí já a origem do acento nacional mesmo antes da formação da linguagem.

Eu não examinarei de maneira nenhuma com Lucrécio, se a invenção do canto é devida à imitação daquele dos pássaros, ou segundo Diodoro, da inspiração do vento nos juncos do Nilo, nem se o eco, após ter por muito tempo assustado os homens pode enfim contribuir para diverti-los e instruí-los. Estas conjecturas incertas não poderiam contribuir para a perfeição da arte e eu só aprecio nas pesquisas sobre a antiguidade as que os modernos podem tirar algum fruto. É aliás bastante inútil recorrer a causas estranhas nos efeitos que podemos deduzir da natureza mesma das coisas, tal é esta modificação da voz que chamamos canto. Modificação que deve ter nascido e se formado naturalmente com a língua: pois é

1 A presente tradução foi realizada com base na edição das Euvres complètes de Rousseau da edição da Pléiade constante no Volume V e publicadas pela Gallimard, 1995. 
bastante claro que cada língua em seu nascimento teve de complementar articulações menos variadas por uma maior diversidade de sons, colocando de início as inflexões e os acentos no lugar das palavras e das sílabas e mais se cantava quanto menos se falasse. Esclareçamos isso com mais cuidado.

Esta é uma observação bastante judiciosa do Sr. Rameau de que o som difere do ruído pelo fato de que o primeiro é apreciado enquanto que o segundo não. O que não impede de forma alguma que o ruído não seja senão o som modificado, como podemos nos convencer com um pouco de reflexão. Basta-me salientar aqui que o som da voz que canta é o mesmo da voz que fala, porém, o som cantante é permanente e sustentado, ao passo que na fala o som está em estado de fluxo contínuo e nunca se sustenta. Com efeito não vemos nada na conformação da glote que possa dar a ideia de dois tipos de voz. Tão logo aquele que fala para numa sílaba, sustenta e prolonga o som de sua voz no mesmo grau, no mesmo instante a vOz falante se transforma em voz cantante e o som se torna apreciável. Além disso, a voz falante faz, como o som musical, ressoar e vibrar os corpos sonoros e se ele ressoa ao mesmo tempo várias cordas significa que as inflexões da voz falante fazem-na passar quase que ao mesmo tempo por um grande número de sons contínuos cujas diversas harmônicas respondem ao mesmo tempo. Enfim, que façamos deslizar o dedo por pequenos intervalos sobre as cordas de um Instrumento o arco delas extrairá sons aos quais não carecem para assemelhar-se à fala senão a articulação das palavras e o timbre da voz humana. De maneira que, com a ajuda de certos pistões semelhantes àqueles destas flautas com as quais as crianças imitam os pássaros, eu não veria como uma ação impossível fazer falar um jogo de palhetas, se eu encontrasse os meios de lhes conferir sua articulação. Mas retornemos à origem da melodia.

Se a voz falante e a voz cantante são absolutamente da mesma natureza a passagem de uma à outra, mesmo falando, torna-se a coisa mais concebível do mundo e a comunicação será tanto mais fácil quanto a língua for mais acentuada. De maneira que, de todas as línguas conhecidas, a língua Grega sendo sem problemas a que tinha mais ressonância e acento, segue-se daí, que ela era também dentre todas, aquela em que o discurso deve ser o mais parecido com o canto.

Nesse momento, eis que nos encontramos fora do país das conjecturas e podemos seguir num passo mais firme na busca da verdade.

A melodia, nascendo com a língua, se enriquece, por assim dizer, com a pobreza desta. Quando tínhamos poucas palavras para expressar muitas ideias, era preciso necessariamente dar diversos sentidos a estas palavras, compô-las de diversas maneiras, darlhes diversas acepções que só o tom distinguia, empregar torneios figurados, e como a dificuldade de se fazer ouvir só permitia dizer coisas interessantes, dizia-se com fogo e justamente porque se dizia com dificuldade. O calor, o acento, o gesto, tudo animava os discursos que precisavam mais se fazer sentir do que se fazer entender. Foi assim que a eloquência precedeu o raciocínio e que os homens tornaram-se oradores e poetas bem antes de serem filósofos.

Houve um tempo, e todos os monumentos da antiguidade nos atestam, em que as almas aquecidas pela admiração dos primeiros conhecimentos e dos homens que os propagaram, fermentavam, por assim dizer, com o levedo da verdade. Os primeiros instantes nos quais o gênero humano abriu os olhos sobre si mesmo foram os momentos de arrebatamento e entusiasmo que todas as descobertas da filosofia não fizeram mais do que 
enfraquecer e abrandar na sequência. Tão logo os grandes homens começaram a ganhar esta ascendência que o verdadeiro gênio adquire sempre sobre o vulgo nos séculos da Barbárie; suas instruções, passando de boca em boca, e logo suas instruções assumiram o aspecto mais favorável ao fogo que lhes inspirava; à memória que lhes fazia conservar, adquiriram número e cadência. O sentimento natural que ditava o número não tardou em metamorfoseá-lo em ritmo pelos retornos iguais dos tempos e das medidas. O gosto da onomatopeia e da imitação, unido à força desigual que as vogais mais ou menos surdas e as diversas articulações davam aos sons das palavras, submeteram a regras constantes o acento gramatical. O acento patético animou tudo, porque, só dizendo coisas importantes e necessárias, não se dizia nada que não fosse com interesse e calor, e finalmente do esforço de reter junto com os versos, o tom com o qual eles eram pronunciados, surgiu então o primeiro germe da verdadeira Música, que não é tanto o acento simples da fala senão esse mesmo acento imitado.

Mal as primeiras centelhas deste gênio celeste agitaram os corações e os povos reunidos se puseram a cantar num tom sublime os deuses que engendravam sua imaginação excitada, os heróis, que deploravam a perda, e as virtudes que seus vícios nascentes tornavam necessárias; todos os seus sentimentos eram êxtases, os rústicos sons de uma flauta de três furos eram suficientes para deixá-los fora de si. Este ardor fervente se transmitindo totalmente à pessoa animou os primeiros passos, o gesto dos espectadores respondia aos discursos do Corifeu e marcava a aprovação universal. Nunca o vão ruído da harmonia perturbou estes divinos concertos. Tudo era heroico e grande nestas antigas festas. As leis e as canções levavam os mesmos nomes nestes tempos felizes; elas ecoavam em uníssono em todas as vozes, passavam com o mesmo prazer por todos os corações, tudo se prestava à adoração das primeiras imagens da virtude e a própria inocência conferia um acento mais doce à voz do prazer. Leitor, perdoai-me este desvio; quem poderia sonhar com o sangue frio com o tempo da inocência e da felicidade dos homens?

Foi assim que tudo o que a arte de comunicar seus pensamentos pode ter de mais patético e de mais tocante, se desenvolveu desde o nascimento desta grande arte, animou os primeiros acentos e deu força e graça ao discurso, mesmo antes que ele tivesse exatidão e clareza.

Foi assim que ao mesmo tempo a língua tornou-se melodiosa e cantante, que a música em lugar de ser uma arte particular, tornou-se uma das partes da gramática e que, enfim, alguém que não soubesse suas regras passava por não saber a língua. Em verdade Pitágoras e Filolau calcularam as relações das consonâncias e de todos os intervalos, e estes conhecimentos foram necessários para a construção e a prática dos instrumentos que só podem ser afinados pelas consonâncias. Mas a constituição dos diversos sistemas dos Gregos prova evidentemente que seus autores não eram guiados por nenhum verdadeiro sentimento de harmonia e que todo aquele que ousasse sustentar o contrário seria rapidamente sobrecarregado com provas e reduzido ao silêncio e ao descrédito. Se nós disputamos tanto tempo sobre a ciência harmônica dos gregos, foi porque essas disputas se davam entre literatos pouco versados na arte, que imaginavam que rápidas noções da nossa música fossem suficientes para julgar a dos gregos, ao passo que com um pouco mais de conhecimento eles teriam visto que estas duas artes não têm, nem podem ter nenhuma parte em comum pela qual pudessem ser comparadas de maneira exata.

[Os gregos só reconheceram como consonâncias às que nós denominamos consonâncias perfeitas. Eles rejeitaram entre seu número as terças e as sextas. Por que isso? 
Porque o intervalo do tom menor ao ser ignorado por eles ou pelo menos proscrito de sua prática, e como suas consonâncias não eram de forma alguma temperadas, todas suas terças maiores eram fortes de um coma, enquanto que suas terças menores eram tão fracas quanto aquelas eram fortes. E por isso reciprocamente suas sextas maiores e menores ficavam alteradas da mesma maneira. Que se imagine agora quais noções de harmonia pode-se ter, e quais modos harmônicos pode-se estabelecer ao banir as terças e as sextas entre o número das consonâncias. Se as próprias consonâncias que eles admitiam lhes fossem conhecidas por um verdadeiro sentimento de harmonia, eles deveriam tê-las sentido alhures que na melodia. Eles, por assim dizer, as teriam subentendido abaixo de seus cantos. A consonância tácita das marchas fundamentais lhes fez dar este nome às marchas diatônicas que elas engendravam. Longe de ter menos consonâncias que nós, eles as tiveram em maior número, e preocupados com o exemplo da baixa $u t$-sol eles teriam dado o nome de consonância ao intervalo de $u t$ a ré.]

Eu rogo aos leitores não se impacientarem. Se eu tomo um tão longo desvio, não é porque eu perco o fim de vista, mas porque não vejo nenhum caminho mais curto para alcançá-lo.

A melodia que resultou dos progressos de que falei, era composta de tempos e de tons, quer dizer, do acento propriamente dito e do ritmo. $\mathrm{O}$ acento era a regra da elevação e da diminuição da voz, o ritmo era o da medida e dos pés. O conjunto tinha como princípio a facilidade da entonação, a propriedade da língua e o prazer do ouvido. Mas, sobretudo, este outro prazer, mais vivo, que vai até o coração e ao qual o do ouvido só serve como veículo.

Como os pés e os versos tomaram naturalmente uma certa medida, os tons e os intervalos tomaram naturalmente uma outra da mesma forma. Esta medida acabou por ser fixada pelos cálculos de Pitágoras e pela ordem mais comum destes intervalos resultou o gênero que se chama diatônico. Este gênero se subdividiu em várias espécies, das quais nenhuma pode ter fundamento harmônico, e se ocorreu que os tons que deles resultavam possuíssem relações que os aproximassem dos nossos, seria um efeito da natureza da prosódia grega e da facilidade que se devia encontrar ao entoar mais estes intervalos do que outros. [Pois entre a modificação muito forte que é preciso dar à glote para entoar continuamente os grandes intervalos das consonâncias, e a dificuldade de apreciar a entonação nas relações muito compostas, o órgão assumiu um meio termo e caiu naturalmente sobre uma marcha diatônica que exaure menos a glote que a entonação das consonâncias, e que é apreciada mais facilmente que os intervalos menores. O que não impediu que os menores intervalos não tivessem também seu emprego em gêneros mais patéticos.]

Que o ritmo ou a medida fosse uma das partes constitutivas da melodia, é o que se deduz unicamente da noção desta melodia que só era a expressão forte, sustentada, e apreciada do acento gramatical e oratório. Pois este acento não consistia menos na duração relativa dos sons do que em seus graus e o número não era menos essencial do que a entonação. Que se os antigos autores distinguem às vezes em seus escritos a melodia do ritmo, o que é raro, é numa distinção puramente metafísica como as duas qualidades do mesmo sujeito, e não como duas partes realmente diferentes; também Aristóteles declara expressamente ouvir ao mesmo tempo o melos e a harmonia, quer dizer, a entonação e o número sob o nome de melodia. 
[Então em que estava pensando o Sr. Rameau ao nos dar como acessórios da melodia a medida, a diferença do alto e do baixo, do doce e do forte, enquanto que todas essas coisas não são senão a melodia em si mesma, e que se nós a separássemos, ela não seria mais nada. Os sons agudos ou graves representam os acentos semelhantes no discurso, os breves e os longos as quantidades semelhantes da prosódia. A medida igual e constante o ritmo e os pés dos versos. Os sons doces e os fortes representam a voz (remissa) ou veemente do orador. Haveria um só homem no mundo tão desprovido de sentimentos para dizer coisas apaixonadas sem jamais adoçar nem reforçar a voz?

Parece que assim como a palavra é a arte de transmitir as ideias, a melodia é aquela de transmitir os sentimentos, entretanto, o Sr. Rameau quer despojá-la de tudo aquilo que lhe serve de linguagem e que ele não pode atribuir à harmonia.

Voltemos por um instante à medida. O que é uma sequência de notas indeterminadas quanto à duração? Sons isolados e desprovidos de todo efeito comum, que escutamos separadamente uns dos outros, e que, ainda que engendrados por uma sucessão harmônica, não oferecem nenhum conjunto ao ouvido, e esperam para formar uma frase e dizer qualquer coisa, a ligação que a medida lhes fornece. Que se apresente ao músico uma sequência de notas de valor indeterminado, ele fará dela cinquenta melodias inteiramente diferentes, tão só com as diversas formas de escandi-las; de combiná-las e variar seus movimentos. Prova invencível de que cabe à medida determinar qualquer melodia. Que se a diversidade de harmonia que podemos lhe dar faz variar também seus efeitos, é porque a diversidade de harmonia ainda provoca realmente tantas melodias diferentes ao dar aos mesmos intervalos diversas colocações na escala do modo, o que muda inteiramente as relações dos sons e os sentidos das frases.] Mas retornemos ao histórico.

Entretanto a língua se aperfeiçoava; a melodia impondo-se ao se impor novas regras, insensivelmente perdeu sua antiga energia, e o cálculo dos intervalos foi enfim substituído pela delicadeza das entonações. Foi assim, por exemplo, que a prática do gênero enarmônico foi abolida pouco a pouco. E quando os teatros tomaram uma forma regular, não se cantava ali senão sob os modos prescritos, e à medida que se aperfeiçoavam as regras da imitação, a língua imitativa se enfraquecia. Mas este progresso foi lento em seu começo e várias causas particulares acelerando-o em seguida, finalmente destruíram todo o encantamento da melodia. Pois nada possui tanto acento quanto a língua natural, que não é senão o grito animal. Os desdobramentos da razão tornaram a língua artificial mais fria e menos acentuada. A lógica sucedeu gradualmente à eloquência, o tranquilo raciocínio sucedeu ao fogo do entusiasmo e à força de se aprender a pensar aprendeu-se a não mais sentir.

O estudo da filosofia e os progressos da razão, que conferiram mais perfeição, e um outro torneio à língua, lhe tiraram assim este tom vivo e apaixonado que havia lhe tornado tão cantante no princípio. Foi então que a melodia, começando a não ser mais tão aderente à linguagem na declamação, assumiu insensivelmente uma existência à parte, enquanto que a música tornou-se mais independente das palavras. Foi assim também que cessaram pouco a pouco esses prodígios que ela havia produzido quando não era senão o acento vivo e apaixonado da poesia e que lhe conferiam este império sobre as paixões, que o discurso humano não experimentou mais na sequência, senão sobre a razão. Da mesma maneira, desde que a Grécia se encheu de Seitas e de filósofos, não se viu mais aí nem poetas nem músicos célebres. Ao cultivar a arte de convencer, perdeu-se aquela de emocionar. Platão 
mesmo, no seio de sua sabedoria, enciumado de Homero e de Eurípides desacreditou um e não pôde imitar o outro.

Logo a servidão acrescentou sua influência à da filosofia. A Grécia a ferros perdeu aquele fogo celeste que só aquece as almas livres e não encontrou mais, para louvar seus tiranos, o tom sublime com o qual havia outrora cantado seus heróis. A mistura dos romanos enfraqueceu ainda mais o que restava de harmonia e de acento na linguagem. O latim, língua mais surda e menos musical, fez mal à música quando ela o adotou. $\mathrm{O}$ canto empregado na capital pouco a pouco alterou o das províncias; os teatros de Roma prejudicaram os de Atenas. Quando Nero ganhava prêmios, a Grécia havia deixado de merecê-los, e a mesma melodia, dividida entre duas línguas, não convinha mais nem a uma nem à outra.

Enfim, aconteceu a fatal catástrofe que deveria aniquilar todos os progressos do espírito humano. A Europa, inundada de bárbaros e subjugada por ignorantes, perdeu ao mesmo tempo suas ciências, suas artes, e o instrumento universal de ambas, a saber, a língua harmoniosa e aperfeiçoada. Esses homens grosseiros, que o norte havia engendrado insensivelmente fizeram com que todos os ouvidos se acostumassem à rudeza de seus órgãos. Segundo o imperador Juliano, eles coaxavam ao invés de falar, e sua voz dura e destituída de acento, era ruidosa sem ser sonora. Todas as suas articulações, sendo aliás rudes e surdas e suas vogais pouco sonoras, eles não podiam senão comunicar a seu canto uma espécie de suavidade que consistia em reforçar o som das vogais para cobrir a abundância e a dureza de suas consoantes.

Esse canto ruidoso, juntando-se à inflexibilidade do órgão, obrigou, esses recémchegados e os povos subjugados que os imitaram, a alongar os sons para lhes conferir mais brilho. A articulação penosa e os sons reforçados concorreram também para expulsar da melodia qualquer sentimento de medida e de ritmo. Como a passagem de um som a outro era sempre a mais difícil, não havia nada melhor a fazer senão deter-se sobre cada um deles o máximo possível. O canto logo passou a ser somente uma sequência aborrecida e lenta de sons arrastados e gritados em altos brados, sem doçura, sem medida e sem graça. E, se alguns sábios observaram de tempos em tempos que era preciso longas e breves no canto latino, pelo menos ficou certo que não se tratava mais de pés e de ritmo nem de nenhuma espécie de canto medido.

O canto, despojado assim de toda melodia e consistindo unicamente na força e na duração dos sons deve ter sugerido, enfim, os meios para tornar-se mais sonoro ainda com o auxílio das consonâncias. Pois várias vozes, incessantemente arrastando em uníssono sons de uma duração ilimitada, encontraram naturalmente e ao acaso, alguns acordes cujas vibrações diversificadas reforçavam o ruído, enquanto que as mesmas vibrações reunidas, tornavam-no mais agradável, e assim iniciou-se a prática do descanto e do contraponto.

Não se poderia dizer por quantos séculos os músicos giraram em torno de questões frívolas que o efeito conhecido de uma causa ignorada lhes fizera ficar agitados por tanto tempo. O leitor mais incansável não pode suportar, em Jean de Muris, o palavrório de oito ou dez extensos capítulos, para saber se, no intervalo da oitava dividida em duas consonâncias, se é a quinta ou a quarta que deve ser grave. E quatrocentos anos depois encontramos ainda em Bontempi enumerações não menos tediosas, de todos os baixos que devem comportar a sexta ao invés da quinta. Entretanto a harmonia tomava insensivelmente os caminhos que a natureza lhe havia prescrito, até que finalmente a invenção do modo 
menor e das dissonâncias, ou dizendo de outra forma, introduziu toda a arbitrariedade da qual ela está cheia e que somente o preconceito nos impede de perceber.

É assim que, a melodia sendo esquecida, e a atenção do músico tendo se voltado inteiramente na direção da harmonia, tudo se dirigiu para este novo objeto. Os gêneros, os modos, a escala, tudo tomou insensivelmente uma cara nova, foram as sucessões harmônicas que regularam a marcha das partes, esta marcha tendo adotado o nome de melodia, não podemos desconhecer, com efeito, nesta pretensa melodia, os traços da mãe que lhe deu vida. E nosso sistema musical, tendo-se tornado, desta maneira, puramente harmônico, não é de se espantar que a melodia fosse afetada e que a música tenha perdido, para nós, grande parte da energia que possuía outrora.

Eis como o canto tornou-se aos poucos, uma arte completamente separada da língua da qual ele retira sua origem. Eis ainda como o sentimento do som e de suas harmônicas, aí fez perder o do acento oral, o da quantidade numérica, e, por conseguinte, da medida e do ritmo. E como enfim, limitado puramente ao efeito físico do concurso das vibrações, a música se achou totalmente privada dos feitos morais que ela havia produzido quando era duplamente a voz da natureza.

Mas quando, introduzindo a música em nossos teatros, quis-se restabelecer-lhe seus antigos direitos e torná-la uma linguagem imitativa e apaixonada, foi então que se precisou aproximá-la da língua gramatical. Donde esta última extraiu seu primeiro ser, e que regulando as modulações da vOz cantante sobre as diversas inflexões que as paixões deram à voz falante, a melodia encontrou, por assim dizer, uma nova existência e novas forças, em conformidade com o acento oratório e apaixonado. Então, já estando submetido às marchas harmônicas que não devíamos ter separado, o canto, rigorosamente subjugado pela língua e constrangido duplamente, pelo sistema harmônico e pela declamação, assumiu em cada país, o caráter da língua do qual tirara sua forma, e tornou-se tanto mais melodioso e variado quanto mais ritmo e acento possuísse esta língua. E naquelas que tendo pouco, tanto de um quanto do outro, estes não são, por assim dizer, senão o órgão da razão; e este mesmo canto permaneceu lânguido e frio, assim como o tom das pessoas que não fazem senão raciocinar. Nestas regiões feitas para a sabedoria, em que o julgamento impera sobre as paixões vivas, onde a melodia tendo adquirido pouca ascendência, a harmonia acabou por conservar toda a sua. E é aí que o prazer físico complementando o prazer moral, faz com que prefiramos os acordes aos cantos e os sons ruidosos de uma voz forte ou de um grande coro aos sons tocantes de uma voz terna e apaixonada.

Todo este histórico está apoiado sobre os fatos e fornece, como podemos ver, conclusões diametralmente opostas ao sistema do Sr. Rameau. Tratemos agora de retornar à essência das coisas, e para evitar todo sofisma sobre suas qualidades, consideremo-las, tanto quanto for possível, em sua própria natureza. Concedamos a um som qualquer e ao concurso de suas harmônicas o efeito mais agradável. Imaginemos uma sucessão de acordes mais simples e mais harmoniosa, ou a mais dura e a menos natural possível. O que pode resultar de tudo isso, senão uma sensação puramente física, e a impressão lisonjeira ou desagradável que fará sobre o órgão a convergência ou a discordância das vibrações deste corpo sonoro? Qual ligação a razão pode perceber entre estas vibrações mais ou menos concordantes e as emoções da alma que passo a passo, segundo a vontade do compositor lançam-na em êxtases com paixões tão opostas? Excluindo-se o caso que diz respeito diretamente à nossa conservação, nunca serão as causas puramente físicas, a nos emocionar até esse ponto. 
Poder-se-á nuançar e combinar as cores o quanto quiser, e mesmo o mais sábio pintor, jamais poderá dispô-las de maneira a excitar nem a piedade nem a cólera. Se ele quiser despertar nossas paixões, que ele se sirva destas mesmas cores para nos fazer representar através do desenho os efeitos morais. Que ele nos pinte o cauteloso Ulisses conquistando o prêmio de bravura sobre o intrépido Ájax. Que ele faça prosternar o desafortunado Príamo aos pés do assassino de seu filho. Que ele nos exponha os adeuses de Andrômaca e de Heitor, e as ternas carícias deste Herói ao seu pequeno Astianax, e o pavor da criança ao ver sobre a cabeça de Heitor tremular o penacho terrível, o sorriso mesclado de lágrimas que esta cena presente e o pressentimento do futuro arranca à mais casta das esposas e à mais infeliz das mães. Eis aí os objetos tocantes com a ajuda dos quais as cores do pintor excitarão em nós o interesse, a compaixão, o terror e todos os movimentos de que a alma é capaz. Sem isso, mesmo o mais sábio físico, tentará sem êxito fazer eruditas dissertações sobre a potência das cores, e sobre as modificações do nervo ótico, ele tentará sem êxito, conduzir, à força de ângulos e refrações, seus raios visuais ao cérebro, e mesmo assim ele jamais poderá levar esta impressão até o coração. Eis o ponto em que o físico se detém, e cabe ao pintor fazer o resto, e ao filósofo explicá-lo.

Enganamo-nos da mesma forma em música, tão logo tomamos como primeira causa a harmonia e os sons, que não são, com efeito, senão os instrumentos da melodia. Não que a melodia, por sua vez, tenha esta causa nela mesma. Mas ela a extrai dos efeitos morais de que ela é a imagem. A saber: o grito da natureza, o acento, o número, a medida e o tom patético e apaixonado que a agitação da alma dá à voz humana.

Esta analogia tão clara e tão simples mostra evidentemente, que o princípio da imitação e do sentimento é tudo na melodia. A harmonia só pode concorrer aqui, tornando as sensações mais lisonjeiras e, por conseguinte, mais interessantes, ou através de mais ou menos ruído, ou reforçando a expressão do canto, e é sobretudo nisso que consiste a utilidade da harmonia na música imitativa. Pois, por mais que ela não seja a fonte, seria, contudo, um grande erro pensar que ela seja desprezível. Isso não muda nada. Ela serve para sustentar a melodia, para determinar a modulação com a precisão mais exata, para tornar o sentimento sempre presente, para reforçar ou subtrair os sons por intervalos mais ou menos sensíveis, e para bem marcar a medida e o ritmo. Serve enfim, para tornar mais sensível este piano-forte que é a alma tanto da melodia quanto do discurso que ela imita. E é desta maneira que a harmonia devolve em parte, à música, o que ela retira de sua energia pela exclusão de uma multidão de intervalos irregulares. Mas se o músico só pensar na harmonia, se negligenciar a parte essencial que é o canto, para correr atrás dos enchimentos [remplissage: partes localizadas entre os baixos e os altos], e dos acordes, ele fará muito ruído e pouco efeito, e sua música atordoante, dará muito mais dor de cabeça do que emoções ao coração.

Não pensemos, então, que através das proporções e das cifras, explicar-se-á algum dia o império que a música tem sobre as paixões. Todas essas explicações são apenas galimatias e farão apenas incrédulos, porque a experiência as desmente sem cessar, e porque não podemos descobrir através delas nenhuma espécie de ligação com a natureza do homem. O princípio e as regras são apenas o material da arte, é preciso uma metafísica mais fina para explicar seus grandes efeitos. 